\title{
Qualidade da formação de pedagogos na perspectiva da oferta do Parfor Presencial
}

Valdinei Costa Souzal

\begin{abstract}
Resumo
O objetivo deste artigo é evidenciar o padrão de qualidade presente na oferta dos cursos presenciais de pedagogia chancelados pelo Plano Nacional de Formação de Professores da Educação Básica (Parfor). A partir de evidências teórico-práticas, assumiu-se como pressuposto de análise que a regulação promovida pelo Sistema Nacional de Avaliação da Educação Superior (Sinaes) não seria capaz de garantir a organicidade do trabalho das diferentes IES no âmbito do Parfor Presencial e, portanto, não garantiria o próprio padrão de qualidade previsto legalmente para essa oferta. Na tentativa de elucidar o efetivo padrão de qualidade em questão, entrevistaram-se os coordenadores dos referidos cursos sobre aspectos de sua organização didático-pedagógica, infraestrutura e corpo docente. Como técnica para tratamento e análise dos dados coletados, utilizou-se a hermenêutica (MINAYO, 2009; 2013) entendida como arte da compreensão de textos, tomados no seu sentido mais abrangente como formas de comunicação humana. No processo de análise, os dados foram contextualizados nas trajetórias históricas, definições legais e conceitos teóricos que envolvem o Parfor, em geral, e o curso de pedagogia, em particular. Os achados revelaram o padrão de qualidade em foco por meio de parâmetros imprecisos, sem indicar um significado representativo daquilo que caracteriza a oferta de um bom curso de pedagogia no âmbito do Parfor Presencial.
\end{abstract}

\section{Palavras-chave}

Qualidade - Parfor - Curso de pedagogia. 


\title{
The Quality of Teacher Training under the "Parfor Presencial"'
}

Valdinei Costa Souza'

\begin{abstract}
This article aims to highlight the quality standards present in courses offered under the National Plan for Basic Schoolteacher Education (PARFOR). Surveying theoretical and empirical evidence, this analysis demonstrates that regulations promoted by the National Higher Education Evaluation System (SINAES) would not be able to guarantee the coordinated work of multiple Higher Education Institutions within the PARFOR; therefore, the required quality standards would not be produced. In an attempt to elucidate the actual quality standards under PARFOR, coordinators were interviewed on aspects of their pedagogical organizing, infrastructure, and faculty for these courses. Hermeneutics that is the art of understanding texts, which are human communication in its broadest form, was used as a technique for processing and analyzing the collected data (MINAYO, 2009; 2013). During the process of analysis, the data were contextualized into historical trajectories, legal definitions, and theoretical concepts involving the PARFOR in general and the Pedagogy course in particular. The findings revealed that quality standards were measured through inaccurate parameters and failed to indicate a representative significance for what characterizes a proper Pedagogy course for the PARFOR.
\end{abstract}

\section{Keywords}

Quality - National Plan for Basic Schoolteacher Education (Parfor) Pedagogy course.

I- Coordenação de Aperfeiçoamento de Pessoal de Nivel Superior (Capes), Brasília, DF, Brasil.

Contact: valdinei.souza@capes.gov.br 
A Política Nacional de Formação dos Profissionais do Magistério da Educação Básica, instituída pelo Decreto n. ${ }^{\circ}$ 6.755/2009 (BRASIL, 2009) - e, dentro dela, o Plano Nacional de Formação de Professores da Educação Básica (Parfor) - agregou ações da Secretaria de Educação Básica do MEC, voltadas à oferta dos cursos presenciais de formação continuada, e ações da Coordenação de Aperfeiçoamento de Pessoal de Nivel Superior (Capes) referentes à oferta da formação de professores a distância, tanto inicial quanto continuada, a partir do Sistema Universidade Aberta do Brasil (UAB). Além de tentar integrar as ações citadas, o Parfor buscou promover, ainda, a oferta da formação inicial de professores na modalidade presencial denominada Parfor Presencial - com orçamento e gestão próprios, no âmbito da Capes.

Nos termos do inciso IV do art. 2. ${ }^{\circ}$ do Decreto n. ${ }^{\circ} 6.755 / 2009$, o Parfor deve buscar garantir o "padrão de qualidade dos cursos de formação de docentes ofertados pelas instituições formadoras" (BRASIL, 2009). No caso do Parfor Presencial, que congrega a grande maioria das matrículas do Parfor, esse princípio se materializou na exigência de conformidade ao Sistema de Regulação do Ensino Superior (e-MEC) - nota da avaliação de curso maior que três ou, na sua ausência, nota da avaliação de instituição igual ou superior a três. Quando as instituições não pertencem ao Sistema Federal de Ensino Superior (originárias de sistemas estaduais e municipais), as regras admitem participação mediante adesão voluntária ao e-MEC ou por meio de autorização do órgão responsável por sua regulação, com anuência da Capes (CAPES, 2014).

No entanto, a regulação do e-MEC, advinda do Sistema Nacional de Avaliação da Educação Superior (Sinaes), não parece ser capaz de garantir o padrão de qualidade na oferta dos cursos do Parfor Presencial. Por um lado, as definições legais do Sinaes restringem suas consequências regulatórias aos cursos de instituições federais e privadas, enfraquecendo a abrangência dos seus pressupostos de qualidade para cursos oferecidos sob a égide regulatória dos sistemas estaduais e municipais de educação. Por outro, tecnicamente, o Sinaes não alcança as turmas especiais do Parfor Presencial, oferecidas com base em projeto pedagógico distinto, corpo docente diverso e infraestrutura alternativa ao que existe nas demais turmas do curso regularmente avaliado.

Além disso, o Parfor Presencial não orientou a reflexão de cursos e instituições sobre problemas conceituais e práticos inerentes ao programa - e não resolvidos pelo Sinaes -, entre os quais se destacaram: i) o perfil diferenciado do aluno (que é um professor em serviço); ii) o projeto pedagógico e a abordagem metodológica para atender professores no exercício da docência, mas sem a formação inicial requerida; e iii) os tempos de formação, uma vez que os professores-alunos não são dispensados das suas atividades laborais para participar dos cursos.

Assim, a despeito da necessidade de orientações básicas sobre o padrão de qualidade para os cursos de formação inicial oferecidos no âmbito do Parfor Presencial, estas não foram construídas. Tal ausência permitiu, então, o questionamento sobre a real configuração desse padrão, particularmente na área de pedagogia ${ }^{1}$.

$\mathrm{Na}$ busca por respostas a esse questionamento, considerou-se que, na educação superior, o conceito de qualidade pode seguir em várias direções, decorrente tanto da subjetividade na apropriação de critérios ou aspectos que o define (marcadamente condicionados a contextos históricos, econômicos, sociais e políticos específicos) quanto da infınidade de situações distintas nas quais ele pode ser aplicado: cursos, instituições, docentes, processo ensino-aprendizagem etc. (HARVEY; GREEN, 1993; BERTOLIN, 2007; BURLAMAQUI, 2008; RIOS, 2010; SOUSA, 2009).

Contudo, essa aparente polissemia do conceito de qualidade não pareceu invalidar a análise do seu significado na educação superior,

1- Do total de 42.096 matrículas registradas no Parfor em janeiro de 2012, 32.562 eram em cursos presenciais de primeira licenciatura, dos quais 40\% na área de pedagogia (Plataforma Freire/Capes). 
uma vez que é possível caracterizar cursos ou instituições como bons ou adequados ao inserilos num contexto histórico-social específico. Ilustrando em nível macro esse entendimento, na década de 1990, a qualidade dos cursos de graduação no Brasil esteve associada à dimensão do desempenho de alunos, aferido em exames nacionais por área de formação. $\mathrm{Na}$ década de 2000, com a implantação do Sinaes, ampliaram-se os indicadores e parâmetros para essa caracterização, passando-se a incluir também aqueles relativos às dimensões infraestrutura, corpo docente e organização didático-pedagógica.

Nesses exemplos, o significado de qualidade não foi absoluto, alterando-se ao longo do tempo. Porém, a cada contexto, a qualidade pode ser entendida a partir de critérios previamente defınidos. Em função dessa compreensão, assumiu-se neste trabalho que o significado de qualidade é passível de identificação sempre que um conjunto de indicadores e parâmetros permite caracterizar o que é bom ou adequado para dado objeto numa circunstância específica.

Tendo como base essa noção acerca do conceito de qualidade, procurou-se nas construções teórico-legais das áreas de formação de professores e de avaliação da educação superior os indicadores e possíveis parâmetros de qualidade a serem observados no âmbito da oferta dos cursos de pedagogia pelo Parfor Presencial. Construiu-se, então, um roteiro de entrevistas composto por nove perguntas abertas, o qual foi aplicado a uma amostra $^{2}$ composta por Dezessete coordenadores dos referidos cursos - representando cerca de 30\% da população formada por 59 sujeitos.

Os relatos foram analisados a partir de uma abordagem hermenêutica (MINAYO, 2013, 2009), que permitiu traduzir fatos concretos, sejam eles tangiveis (características ou aspectos visíveis) ou intangíveis (ideias, percepções etc.),

2- Essa amostra respeitou as características institucionais e regionais dos cursos dos cursos de pedagogia do Parfor Presencial, tendo sido escolhida de forma sistemática com início aleatório e intervalo de amostragem igual a três. por meio de indicadores não numéricos. No processo de análise, destacaram-se ocorrências representativas da qualidade da oferta dos cursos, objetivadas pelos trechos mais relevantes do conteúdo das entrevistas. Esses trechos foram classificados por unidades de sentido, estabelecendo-se os parâmetros de qualidade para os indicadores previamente sugeridos pela discussão teórica, ao mesmo tempo em que se acrescentaram outros indicadores, como desdobramentos da própria realidade empírica. No seu conjunto, a análise permitiu contextualizar os dados coletados, oferecendo respostas ao questionamento que motivou 0 presente artigo, conforme detalhado a seguir.

\section{A oferta da pedagogia no Parfor Presencial}

A realidade reportada pelos dados analisados indicou uma diversidade de parâmetros por meio dos quais os cursos presenciais de pedagogia do Parfor apresentaram o que é bom ou adequado para sua oferta. Tal diversidade se referiu tanto aos projetos pedagógicos e à concepção de formação a eles inerentes quanto a sua inter-relação com o perfil dos egressos e com a organização didático-pedagógica dos cursos.

Especificamente sobre concepção de formação do pedagogo os dados apontaram diferenças de percepções entre os coordenadores sobre os parâmetros de um bom curso. A maior parte dos entrevistados (mas não a maioria absoluta) associou tal configuração a uma articulação entre teoria e prática, em um sentido muito próximo àquele definido por Araújo (2009) como racionalidade prática (focada no conhecimento decorrente da prática, por meio da reflexão sobre a ação e voltada à realidade concreta), assim expressado em seus relatos:

[Nós temos no curso] numa perspectiva de reflexividade, [...] baseada mais numa racionalidade prática do que numa racionalidade técnica. (Coordenador K). 
[Temos] uma visão de que a teoria e a prática são indissociáveis. [...] A gente valoriza muito a questão da formação teórica do aluno, articulada a conhecimentos práticos, mas a concepção teórica aqui é muito bem consolidada. (Coordenador N1).

Porém, alguns coordenadores destacaram a importância da formação teórica, fazendo uma espécie de contraponto na associação entre teoria e prática. Inclusive, um dos entrevistados pontuou como concepção de formação docente do curso, justamente, a sólida base teórica, numa perspectiva de aproximação ao conhecer-na-ação, descrito por Schön (2000). Conforme afirmou:

[...] existem certos conhecimentos que são necessários para a prática profissional, $\mathrm{o}$ curso tenta se esmerar na transmissão desses conhecimentos. Na medida em que ele consegue alcançar esse objetivo, contribui para o que se chama de profissionalização. (Coordenador J).

Adicionalmente, esteve presente também nas falas dos coordenadores a concepção de formação docente na perspectiva de racionalidade crítica, nos termos definidos por Araújo (2009) como voltado a reflexões para a compreensão e a transformação social:

Alfabetização não é só letramento, também é política. (Coordenador P).

[Buscamos formar um] profissional crítico transformador. Que não tem receita, mas que observa, analisa e transforma a sociedade sempre para melhor. (Coordenador Q).

Embora tais perspectivas, tratadas de forma polarizada na teoria, não neguem existir certa reciprocidade entre elas, tal possibilidade não pareceu permear a realidade dos cursos de pedagogia do Parfor. A partir dos dados, emergiram ideias que pareceram reger o processo de formação docente no Parfor, sem que se pudesse garantir uma articulação entre elas. Com isso, identificou-se um conjunto de sentidos diferenciados em torno da concepção de formação docente, sem que tais sentidos pudessem ser articulados em torno de fundamentos basilares que apontassem, nesse aspecto, um significado da qualidade efetivamente compartilhado pelos cursos do Parfor.

De forma semelhante, na discussão sobre os projetos pedagógicos dos cursos (PPC), foram reportados como parâmetros positivos tanto os formatos especialmente desenhados para atender à demanda da formação de professores em serviço quanto a reprodução de projetos pedagógicos em uso. Nesse caso, o significado de qualidade buscado pelo Parfor em relação ao PPC colocou lado a lado projetos novos, especialmente desenhados para atender o público-alvo do Parfor, com projetos regulares, submetidos às avaliações do Sinaes, mas, em tese, menos adequados à proposta de formação inicial de docentes que já exercem a profissão.

Em decorrência dessa realidade, observou-se entre os cursos analisados uma diversidade na definição do perfil do egresso formado pelo curso, bem como a concepção de docência a ele associada entre os diversos projetos. Os dados revelaram que quando os coordenadores assumiram a existência de projetos pedagógicos diferentes entre as turmas do Parfor Presencial e das demais turmas do curso regular (sete casos na amostra de dezessete entrevistados), o perfil de formação do egresso revelou-se voltado à atuação na educação infantil e anos iniciais do ensino fundamental, em detrimento da formação na área de gestão escolar, conforme ilustram relatos a seguir:

[Formamos] pessoas que vão atuar principalmente no ensino [e não] em outros cargos, [como os] de gestão ou de supervisão. (Coordenador D).

Nós somos um curso de licenciatura em pedagogia que tem como eixo principal a docência na educação infantil e nos 
anos iniciais e abordamos alguns aspectos relacionados à gestão. (Coordenador $\mathrm{G}$ ).

[Formamos] o professor para dar aula. Ele não está sendo formado para ser gestor. (Coordenador P).

Apenas um dos coordenadores, entre aqueles que afirmaram possuir PPC nas turmas do Parfor diferente daquele das demais turmas, revelou que o perfil do egresso do curso agregava a preparação do gestor, e não só do docente. Em uma perspectiva de docência ampliada $^{3}$, esse coordenador destacou que seu curso prepara o egresso "para atuar em séries iniciais, na educação infantil e nos processos de gestão” (Coordenador K).

Já os demais coordenadores - que declararam que as turmas do Parfor seguiram os mesmos projetos pedagógicos do curso regularmente oferecido pela IES $(n=9) \quad-$ indicaram o perfil do egresso por meio da sua atuação em sala de aula, associada à gestão em espaços escolares e não escolares:

0 foco da atuação [dos] alunos [é o trabalho nas] séries iniciais, educação infantil e gestão. (Coordenador B).

[Formamos] professores para atuar na educação infantil, ensino fundamental e gestão. (Coordenador C).

[Formamos] o professor da educação infantil [e fundamental], com possibilidade de atuação em gestão. (Coordenador N2).

Essas diferenças nas propostas de perfil de atuação dos egressos, evidenciadas pelas falas dos coordenadores, puderam ser associadas, por um lado, à proposta do Parfor de fazer a formação em serviço de professores, mas também

3- Como esclarecem Aguiar e Melo (2005, p. 126-127), pode ser entendida como "fulcro de articulação dos diversos conhecimentos aportes teóricos da pedagogia e das ciências da educação e de outros conhecimentos especializados e daqueles produtos das práticas escolares e não escolares". a pouca clareza sobre a identidade profissional do pedagogo expressada pelas Diretrizes Curriculares Nacionais (DCN) do curso (BRASIL, 2006). Se por um lado, o texto desse documento legal garantiu que a base de formação do pedagogo é a docência, por outro, não pareceu garantir que essa docência fosse aquela identificada por Aguiar et al. (2006) em seu sentido amplo, a qual deve concatenar as duas pontas da formação do pedagogo - professor e especialista em educação.

As diretrizes da licenciatura em pedagogia foram construídas sob a base de um curso historicamente criado para atender à formação de especialistas em educação, conforme estabeleceu o Decreto-Lei n. ${ }^{\circ}$ 1.190/1939 (BRASIL, 1939). Porém, na oferta do Parfor Presencial, não se garantiu que a formação desse docente levasse em consideração a necessidade de conhecimento de gestão da educação em espaços escolares e não escolares.

Tal realidade evidenciada pelos dados da pesquisa pareceu ter reforçado os alertas de Libâneo (2006), Pimenta, Franco e Libâneo (2010), e até mesmo de Rodrigues e Kuenzer (2007) de que a proposta de docência ampliada, sintetizada nas diretrizes da licenciatura em pedagogia, poderia reduzir o curso à docência stricto sensu, esvaziando-o. Alguns coordenadores assim ponderaram sobre essa questão:

0 Conselho deliber[ou] uma coisa escandalosa para fragilizar e fragmentar a formação dos professores. A formação vai sendo precarizada em vez de proporcionar uma solidez no aspecto teórico, de habilidades e valores em cada tipo de formação. (Coordenador N2).

0 que significa ser pedagogo? [...] Eu acredito que não esteja ainda suficientemente claro em termos de área. [...] Quando os alunos me perguntam em gestão e supervisão: 'professora, mas na escola que eu atuo, por exemplo, a legislação municipal, o regimento diz que para ser diretor de escola eu tenho 
que ter uma graduação e não importa se ela é na área da pedagogia ou não'. [...] Essa confusão em torno da identidade da área também faz com que alguns campos de atuação se enfraqueçam, por mais que se fale que alguns lugares, por excelência, são lugares para pedagogos. (Coordenador A).

Esses fragmentos das falas trouxeram aspectos relevantes que não estão sendo adequadamente discutidos no âmbito da política de formação docente, nem nos processos regulatórios dos cursos de pedagogia, a saber: a organização da formação inicial do docente numa perspectiva continuada; a profissionalidade do pedagogo em sua relação com a organização do trabalho escolar; e a própria organização dos cursos de pedagogia em função das discussões anteriores.

Conforme relatos, a organização do trabalho escolar apareceu afetada pela dualidade identificada nos perfis do egresso do curso de pedagogia - o professor stricto sensu e o professor-especialista. Além disso, aparentemente, a inexistência de requisitos formativos para o exercício de atividades administrativo-pedagógicas no âmbito escolar enfraqueceu os argumentos em prol desses conteúdos apenas nos cursos de pedagogia, uma vez que as demais licenciaturas ficaram fora de formação específica nesses temas. Nesse sentido, os dados sugeriram a necessidade de aprofundamento da discussão da docência ampliada no que tange aos seus reflexos não só no processo formativo docente, mas também na qualidade do trabalho escolar.

Além disso, os dados revelaram certa preocupação de alguns cursos presenciais de pedagogia do Parfor em torno dos reflexos da dualidade do perfil formativo dos seus egressos sobre a qualidade do curso. Tal preocupação pareceu ilustrar a necessidade de a área ampliar as discussões em torno da formação inicial, notadamente no que tange sua integração com a formação continuada, conforme sugere a tendência de organização sequenciada da formação docente ao redor do mundo (OCDE, 2011).

Há que se ressaltar, no entanto, que, para uma parte dos coordenadores, a perspectiva de docência ampliada e a possível dualidade no perfil formativo do pedagogo não se reverteu necessariamente em um problema concreto, como deixaram entrever:

As diretrizes têm essa determinação. [...] A gente faz o máximo possível para contemplar as diretrizes. (Coordenador C).

0 bom gestor [...] é um bom professor. 0 bom professor é um bom gestor [...]. Então, nós entendemos que estamos de certa forma com a qualidade necessária para que ele, indo para uma área ou outra, consiga lidar com as especificidades do cotidiano. (Coordenador J).

A nossa ênfase é na formação do professor, mas a gestão está inserida nesse contexto e que faz parte da formação do professor. A gente tem conseguido distribuir bem. (Coordenador Q).

A maioria dos coordenadores, porém, não se posicionou ante a possibilidade de a docência ampliada dificultar a definição do perfil do egresso do curso entre o professor stricto sensu e o professor-especialista. Para eles, tal questão foi relacionada a aspectos desconexos do curso, tais como a competência profissional do professor-formador do curso do Parfor como um especialista na sua área de atuação, passando pela atuação dos gestores municipais na liberação dos professoresaprendizes para realizar o curso do Parfor e indo até as práticas de alguns dos alunos como gestores na sua atuação profissional. Todavia, entre aqueles que não se posicionaram em relação à docência ampliada, muitos resumiram a questão a uma dificuldade de tempo para atender à proposta, sem entrar no mérito sobre sua adequação ou não: 
Tive dificuldade em trabalhar com essa perspectiva de docência ampliada [...]. É muita exigência para tão pouco tempo. (Coordenador B).

[Os alunos] são mais preparados para a educação infantil e anos iniciais. Há o estágio de gestão e eles têm uma disciplina de gestão e um estágio. Ali é um tempo curto, embora tenha a disciplina de políticas educacionais e legislação. (Coordenador I).

Então, a gente faz uma crítica de que é muita coisa para a gente trabalhar com o nosso aluno [...] 0 nosso aluno é formado para essas três frentes e o do Parfor também. (Coordenador N1).

Em função da diversidade de perfis identificados para a atuação dos egressos, a organização didático-pedagógica dos cursos analisados terminou por refleti-los em relação a estágios, conteúdos curriculares, atividades complementares e ao próprio desenvolvimento do curso, sem que fosse possível traduzir o conjunto de parâmetros identificados em um significado inteligível para essa qualidade.

\section{Estágios}

Do ponto de vista dos estágios, identificou-se uma variedade de áreas para o seu desenvolvimento, entre as quais sempre estiveram presentes a de educação infantil e ensino fundamental, conforme sugeriram as DCN do curso. Chamou positivamente à atenção a possibilidade de estágios específıcos nas áreas de educação de adultos e educação especial em um dos cursos observados. Também se destacou na realidade de alguns casos a possibilidade de os estágios na área de gestão se dividirem em espaços escolares e não escolares, enquanto que, em outros, a área de gestão inexistia como opção para o exercício da prática profissional.

No que se referiu à obrigatoriedade dos estágios, na maior parte dos casos, os coordenadores afirmaram dispensar, nos termos legais, o aluno do estágio naquela área em que ele estava atuando, exigindo a carga horária completa apenas nos casos em que o professor-aprendiz não estava em atuação como gestor ou como professor em turmas de nível diferente. Por outro lado, pelo menos dois dos modelos de estágio exigiram a efetiva participação dos professores-aprendizes, a despeito da possibilidade de dispensa legal. Como justificativa para essa não dispensa, os coordenadores desses cursos argumentaram que o momento de estágio se configurava oportuno para que o aluno pudesse refletir sobre o trabalho que vinha desenvolvendo no seu cotidiano como professor da educação básica. No entanto, em um desses casos, se exigiram estágios apenas naqueles níveis para os quais os alunos estavam em atuação em sala de aula, dispensando-os dos demais.

Além disso, os estágios nos cursos de pedagogia do Parfor ocorreram tanto sob a supervisão direta de um professor no espaço escolar quanto de forma mais remota com a apresentação de relatórios ou documentos comprobatórios de determinadas atividades. Em alguns casos, as experiências de estágio foram compartilhadas por meio de seminários, nos quais houve apresentação e debate das experiências adquiridas por intermédio de trabalho de investigação, estudo de caso ou outra atividade. Ressaltou-se, ainda, que, independentemente da forma como os estágios foram tratados entre os cursos da amostra, eles foram defendidos como adequados à concepção de qualidade identificada - formação teórica sólida, voltada para a reflexão crítica e transformadora da prática docente.

Em termos institucionais, encontraramse estágios organizados por meio de ações colaborativas dos professores-aprendizes com escolas nas quais atuavam como professor ou em outras, escolhidas em acordo com as IES. Nesse aspecto, chamou atenção a pouca incidência de convênios firmados entre as instituições ofertantes dos cursos e os espaços 
de realização do estágio, independentemente do fato de os alunos serem também professores da educação básica. Mesmo porque, em alguns casos, a situação do aluno-professor não garantiu tranquilidade do curso para a organização das experiências de exercício profissional, tendo em vista a precariedade dos contratos desses discentes com as redes públicas de educação básica, inclusive expondo-os ao constrangimento de dividir o espaço do estágio com professores regentes, para os quais perderam o emprego.

No que se refere às dinâmicas de condução desses estágios, também se encontrou uma diversidade na organização pelos os cursos. Todas elas foram declaradas pelos coordenadores como voltadas à formação com qualidade do pedagogo, podendo estar associadas a (i) observações empíricas, seguidas de discussão em sala de aula; (ii) à pesquisa com geração de relatório; (iii) a projeto de aprofundamento teórico e intervenção ou, até mesmo, (iv) às práticas de ensino. Vale ressaltar que apesar de a docência ter sido assumida como base da formação do pedagogo pelas diretrizes curriculares do curso (BRASIL, 2006), as dinâmicas de condução dos estágios não trouxeram a prática de ensino como central entre os modelos adotados.

Conforme asseverou Pimenta (1995, p. 61) “a essência da atividade (prática) do professor é o ensino-aprendizagem”. No entanto, como foi possível depreender, as experiências de estágios nos cursos de pedagogia do Parfor Presencial ocorreram das formas mais variadas sem que, necessariamente, o professor em formação tivesse assumido uma sala de aula ou exercido uma atividade vinculada à orientação pedagógica, à direção escolar, bem como ao desenvolvimento de práticas educativas ou de planejamento em ambientes não escolares.

\section{Conteúdos curriculares}

No que se referiu ao tratamento dado aos conteúdos curriculares, as informações prestadas pelos coordenadores confirmaram o diagnóstico apresentado por Gatti (2012) de que os cursos do Parfor pouco inovam. Para a autora, inovação pode ser entendida como a superação das "divisões clássicas entre tópicos e subtópicos disciplinares [...] por uma concepção de ensino mais integradora, e quando a proposta didática se apoia em meios diferenciados de ensino" (GATTI, 2012, p. 10). Operacionalmente, tais inovações se materializariam, na visão da autora, por meio de: i) estrutura curricular em módulos temáticos e não módulos disciplinares, ou disciplinas, evitando-se a multiplicação de conteúdos fracionados; ii) metodologias de problematização; iii) utilização de metodologias de caso e incidentes críticos; ou, iv) oficinas com propósitos integradores de conhecimentos e práticas. Considerando essa categorização, apenas foi possível identificar propostas inovadoras em três casos, conforme expressaram:

0 currículo integrado é assim, nós não partimos da teoria, para depois ir para a prática [...]. Por exemplo, em vez de a gente ter aquelas disciplinas fragmentadas como história da educação, sociologia, [...] nós estudávamos a nossa história local até chegar lá na Grécia antiga. Então, assim, relacionava a teoria e a prática desde o primeiro semestre e rompia com essa fragmentação da disciplina colocando blocos [...]. (Coordenador B).

Estruturamos em oito blocos, mas agregamos esses blocos no que a gente chama de fundamentos sociológicos da educação; fundamentos filosóficos da educação (fundamentos metodológicos estão aqui); fundamentos psicológicos; fundamentos históricos; fundamentos político-administrativos; disciplinas da área pedagógica - pedagogia e didática e os ensinos; planejamento e avaliação; e, áreas conexas (educação especial etc.) (Coordenador E). 
0 curso é organizado por eixos e cada eixo tem alguns módulos [...]. No primeiro eixo, de contextualização, [...] nós tivemos um módulo que chamamos de fundamento da educação. Dentro desse módulo, vários professores trabalharam [...], procurando estabelecer um diálogo entre os aspectos relacionados à história da educação, sociologia, filosofia, antropologia [...] (Coordenador G).

\section{Atividades Complementares}

Os coordenadores também foram questionados sobre a qualidade do curso refletida por meio das atividades [curriculares] complementares (ACC). No entanto, o conjunto dos relatos fez emergir uma concepção de ACC como espécie de apêndice do processo de formação, utilizada como espaço para suprir deficiências de formação da educação básica - oficinas de interpretação de texto, desenvolvimento da habilidade de escrita e até mesmo alfabetização digital - ou como a prática inerente à articulação das disciplinas teóricas com a realidade educacional. Em alguns casos, as atividades complementares foram apresentadas inclusive com propósito de aprofundamento teórico - e não prático, como definido nas DCN - consistindo em fichamentos de livros, presença em aulas inaugurais e participação em cursos de curta duração, conforme alguns trechos ilustrativos apresentados a seguir:

A gente oferece palestras, cursos e semanas
de estudos em pedagogia, aula inaugural,
[além de] grupos de estudo, de pesquisa
e de projeto de extensão [...]. Tudo que
envolve atividades acadêmicas e também
culturais. (Coordenador Q).

[Consideramos como ACC a] participação em eventos, trabalho voluntário na área de educação; leitura de alguns livros indicados pelos professores, filmes que fazem parte do conteúdo. Projetos de extensão, de pesquisa [...] (Coordenador D).

Seminário interno focando questões relativas ao trabalho deles. Qualquer atividade realizada. Seminários, colóquios, semanas [...] (Coordenador N2).

Tais relatos demonstram, de forma contextualizada, a proposta pouco clara das DCN da licenciatura em pedagogia sobre as ACC e sua relação com as atividades teórico-práticas, bem como na sua relação com as demais práticas previstas no documento legal - estágio e práticas de docência e gestão educacional. Conforme definido no inciso III do art. $7 .^{\circ}$ das referidas diretrizes, as atividades teórico-práticas precisam ser individualizadas e sistematizadas no currículo dos cursos, de forma a integralizar cem horas, correspondendo às atividades de iniciação científıca (IC), de extensão e de monitoria. Embora nas DCN não haja uma posição explícita sobre os objetivos de tais atividades, foi possível entendê-las como uma oportunidade diferenciada da prática do estágio - para que os alunos pudessem aprofundar conhecimentos em campos específicos da educação, entre outros, educação especial, indígena etc. Além disso, segundo o inciso legal em foco, para cumprir a carga horária prevista para as atividades teóricopráticas deveriam contemplar, obrigatoriamente, os três aspectos previstos (IC, monitoria e extensão), uma vez que o conector utilizado é o “e”, não “ou”.

Mesmo diante dessa pouca clareza das DCN da licenciatura em pedagogia sobre as ACC, elas puderam ser entendidas como uma das possibilidades de integralização curricular, estando associadas às atividades teóricopráticas - monitoria, IC e extensão, que juntas integram cem horas de curso - e ao TCC -, cuja carga horária não foi previamente estabelecida, mas deve estar contemplada entre as 2.800 horas de atividades formativas definidas para o curso, nos termos do inciso I do art. $8 .^{\circ}$ das DCN da pedagogia (BRASIL, 2006). Seguindo 
essa perspectiva de análise, entendeu-se que as atividades complementares visam proporcionar, no seu conjunto, vivências em modalidades e experiência educacionais variadas aos alunos e não se confundem com as práticas de docência e gestão educacional.

Práticas de docência e gestão educacional se materializam, então, como um quarto conjunto de práticas - os três primeiros conjuntos de práticas foram denominados de: i) atividades teórico-práticas; ii) estágios; e iii) ACC. Conforme definido no art. $8 .^{\circ}$, inciso II, das DCN da licenciatura da pedagogia, esse quarto conjunto de práticas deve permitir a integralização curricular que propicie "aos licenciandos a observação e acompanhamento, a participação no planejamento, na execução e na avaliação de aprendizagens, do ensino ou de projetos pedagógicos, tanto em escolas como em outros ambientes educativos" (BRASIL, 2006).

Essa interpretação, no entanto, não se refletiu na realidade encontrada na oferta presencial de pedagogia do Parfor. 0 que se percebeu foi que as práticas de docência e gestão educacional, assumidas nesta análise como atreladas às disciplinas teóricas como o seu componente prático, foram entendidas como atividades complementares. Por sua vez, entendendo-se as práticas de docência e gestão educacional como atividades complementares, surpreendentemente, estas passaram a se refletir na fala dos coordenadores como detentoras da obrigatoriedade de totalizar carga horária de cem horas. Por consequência, as atividades teórico-práticas originalmente previstas nas DCN do curso, como monitoria, IC e extensão, ficaram descaracterizadas, inclusive na sua natureza de possuir carga horária específica e obrigatória voltada ao tratamento de conteúdo específico do campo da educação. Nesse contexto confuso, em que uma prática foi tomando o lugar legalmente previsto para outra, o trabalho de conclusão de curso, definido expressamente pelas DCN como atividade complementar, não foi referenciado por parte dos coordenadores em seu relato sobre a qualidade dos cursos coordenados por eles, conforme informaram:

[...] diversas oficinas pedagógicas são computadas como ACC. No início do curso, [os alunos] recebem uma lista com o que pode ser agregado de ACC, [por exemplo] experiências em conselhos escolares, em espaços não escolares, em gestão [...]. Aí eles são orientados a cumprir 200 horas [dessas atividades]. (Coordenador E).

[...] então eu posso estar em sala de aula por 50 horas e colocar 10 horas como atividades complementares: uma visita à escola, uma visita técnica, ou um filme. [...] 0 professor tem a liberdade de criar essa atividade [...] (Coordenador M).

É preciso reconhecer, no entanto, que essa confusão em torno das atividades complementares se deve à forma como o TCC e as atividades de monitoria, de iniciação científica e de extensão foram associados pelo inciso III, art. 8. das Diretrizes da pedagogia (BRASIL, 2006) "às disciplinas, áreas de conhecimentos, seminários, eventos científico-culturais, estudos curriculares de modo a propiciar vivências em algumas modalidades e experiência”. Tomadas dessa forma, aparentemente as cem horas de atividades teórico-práticas, exigidas pelas DCN da licenciatura em pedagogia, foram entendidas por alguns dos cursos como práticas de docência e gestão educacional (complementando carga horária teórica das disciplinas teóricas) ou como vivência em algumas modalidades ou experiências (atividades complementares), conforme expresso nas falas anteriormente transcritas e nesta a seguir:

Então cada professor de cada disciplina, de acordo com os critérios pré-estabelecidos e fixados no projeto pedagógico do curso, vai passar as atividades que eles têm que desenvolver, articulando-as às disciplinas. 
Além disso, tem ACC que são atividades culturais que também estão especificadas no projeto pedagógico e são acompanhadas por um professor do curso. Eu tenho um professor responsável para cuidar dessas atividades complementares. (Coordenador C).

De qualquer forma, apesar de a norma não ser clara, esse fato não foi capaz de explicar como as atividades complementares se reverteram, no contexto de alguns cursos de pedagogia do Parfor, em oficinas ou atividades para a recuperação de deficiência de formação básica dos alunos (português, informática, produção de texto etc.). Sem se questionar a necessidade ou adequação de tais oficinas, identificou-se apenas que tal procedimento não pareceu estar formalmente amparado nas DCN do curso, uma vez que não possuem vinculação específica aos núcleos de estudos que definem o currículo previsto no art. $6 .^{\circ}$ das referidas normas (BRASIL, 2006). Ainda assim, conteúdos relativos à formação no ensino médio estão ocupando a carga horária obrigatória de um curso de nível superior, conforme evidenciado por alguns coordenadores:

Outra [atividade] que a gente fez foi [promover] oficinas à medida que percebíamos que era necessário [...]. Então, uma das oficinas que tivemos foi a de informática, tivemos várias de escrita, e agora no final do curso teremos que fazer novamente [...] (Coordenador G).

Eu criei, para atender as atividades complementares dos projetos pedagógicos, oficinas pedagógicas de informática, elaboração de resenhas, resumos, principalmente de pesquisa, cinema na escola, brinquedoteca, jogos didáticos e inglês [...]. Então, a gente dá esses complementos, que são na maioria 20 horas a carga horária de cada uma dessas. (Coordenador P).
Apenas para ilustrar as possibilidades que poderiam ser assumidas em torno dos conteúdos complementares, que não apenas a recuperação dos alunos em conhecimentos próprios da educação básica, destacaram-se as sugestões de Gatti (2012), a saber: oficinas para elaboração de materiais didáticos; oficinas voltadas ao pensamento lógicomatemático; estudos sobre a dimensão ético-política da prática docente; didática e currículo da educação básica, diversificada por área e nível; atividade de experiência social na comunidade do entorno escolar; questões de escolas urbanas, suburbanas e rurais; análise qualitativa da instituição escolar; saber específico da área e seu papel no currículo escolar; desenvolvimento de atividades de planejamento de ensino; planejamento do trabalho escolar; construção e experimentação de projetos de ensino; e diferenciais cognitivos entre crianças e adolescentes.

\section{Desenvolvimento do curso}

Em relação ao desenvolvimento do curso, também se encontrou um movimento dialético naquilo que foi considerado como facilitador ou inibidor da qualidade dos cursos em análise. Embora a questão da experiência prática dos alunos tivesse sido destacada na quase unanimidade das falas dos coordenadores, não se observou consenso sobre o impacto de tal característica dos alunos para a qualidade da licenciatura em pedagogia. Por um lado, a proximidade com a sala de aula foi muito elogiada como oportunidade maior de apropriação dos conteúdos teóricos discutidos. Por outro, não deixou de ser vista como barreira à própria profissionalização do professor-aprendiz, conforme expuseram alguns coordenadores entrevistados:

Essas professoras têm contato diário com a sala de aula, com a gestão escolar. Muitas delas já foram diretoras ou são diretoras de escolas, sem ter curso de pedagogia 
[...]. É mais fácil incorporar o conteúdo a um professor que não atuou em escolas do que aquele que cristalizou processos e conhecimentos não científicos e do senso comum na prática do seu cotidiano. (Coordenador P).

Os alunos do Parfor são professores que já têm experiência. Algumas experiências que a gente manifesta na prática como portadores de vícios, mas outras também portadoras de virtudes. (Coordenador K).

As repercussões da realidade do aluno com experiência docente se refletiram ainda em cuidados quanto à periodicidade da oferta, à metodologia de trabalho e aos demais aspectos envolvidos na organização do curso. Sobre a periodicidade na oferta, em boa parte dos cursos, as aulas se concentraram nos meses de janeiro e julho, fınais de semana e à noite. Outra parte menor de cursos manteve sua rotina regular de oferta de disciplinas, sem que se pudesse constatar o impacto de um ou outro procedimento sobre a evasão ou a reprovação de alunos para que se pudesse considerá-los como adequados, ou não, em relação às diversas realidades presentes no Brasil.

Contudo, alguns coordenadores de cursos localizados principalmente na região norte revelaram que, além de ser necessária a alteração do período da oferta de disciplina, a questão do planejamento do cronograma de aulas apareceu como imprescindível para garantir a presença dos alunos nos dias de aula. Além disso, pelo menos um coordenador do norte e um do nordeste apontaram expressamente a necessidade de que as atividades teóricas se limitassem à carga horária presencial prevista: todas as leituras e exercícios propostos deveriam ser realizados exclusivamente no período das aulas, sob a supervisão do professor. No entanto, as repercussões desse procedimento na qualidade da formação de um estudante da educação superior não ficaram claras, tampouco se a permanência dos estudantes no curso seria um indicador de qualidade mais importante do que o desenvolvimento de sua autonomia intelectual propiciada pelos momentos de reflexão individual. Os relatos desses casos pareceram se reportar mais à conveniência dos estudantes do que efetivamente a uma contribuição ao processo de crescimento deles como profissionais, como seguem:

Evitamos fazer trabalhos em casa. Eles fazem em sala de aula com o professor. (Coordenador F).

Por isso que eu falei com você, [o professor] tem que ler com o aluno, para que o aluno possa começar a ler [...]. Nós pedimos para que o professor trabalhe na semana tarefas obrigatórias. Para casa, os alunos não cumprem [...]. Então, a qualidade para mim, envolve tudo isso. (Coordenador P).

Destacou-se, no entanto, certo consenso na afırmação de que as deficiências de formação básica apresentadas pelos alunos da pedagogia do Parfor não se distanciavam muito das deficiências apresentadas pelos alunos regulares dos cursos:

$\mathrm{Eu}$ fiz algumas avaliações, semelhantes ao Enade, entre alunos do Parfor e do não Parfor. Com isso, nós verificamos que esses alunos [do Parfor] não têm diferenças dos demais. (Coordenador B).

Os problemas de formação básica são idênticos [...]. Problemas de escrita, concordância, plágio, todos iguais. Lá e cá. [Parece-me] que isso vai além da especificidade desse curso: envolve condições sociais mais amplas. (Coordenador J).

As principais diferenças reportadas para justificar tratamentos diferenciados entre as turmas do Parfor e as demais foram localizadas no cansaço proveniente de alunos trabalhadores; no tempo de afastamento da rotina de estudo; 
na maior dificuldade no uso da tecnologia da informação; nas responsabilidades familiares mais pesadas; e no menor tempo disponível para participação das atividades extras propostas. Em sintese, puderam-se resumir as diferenças em torno da idade mais avançada dos alunos do Parfor, associada a todas as virtudes e limitações impostas por ela, quando comparadas às dos alunos mais jovens, em maior número dos cursos regulares.

Adicionalmente, pouco se pôde inferir sobre as repercussões do processo de avaliação de aprendizagem na organização das turmas do Parfor em relação às demais turmas do curso. As experiências compartilhadas apresentaram como modus operandi em caso de reprovação, desde a participação do aluno do Parfor em outras turmas do curso regular, passando pela avaliação em várias etapas para evitar a reprovação e indo até a participação do aluno em turmas do Parfor oferecidas pelas IES, podendo inclusive ser em outra área de licenciatura.

Observou-se também certa tendência entre os coordenadores de considerar benéfica a atenção mais próxima que tem sido dada às turmas do Parfor Presencial da pedagogia em termos de repercussão da qualidade da sua formação. No entanto, essa forma de atuação foi destacada por apenas alguns dos entrevistados. Com isso, ações como as de planejamento da oferta das disciplinas, acompanhamento e orientação sobre a atuação metodológica do professor na condução das turmas, bem como a atenção e acompanhamento mais próximo ao aluno, foram observadas apenas em uma pequena parcela dos cursos sob chancela do Parfor.

\section{Considerações finais}

A discussão dos dados revelou uma definição imprecisa do padrão de qualidade dos cursos analisados, sem indicar um significado representativo daquilo que caracteriza a oferta de um bom curso presencial de pedagogia no âmbito do Parfor Presencial. Nesse sentido, não foi observada a predominância de características que pudessem individualizar a concepção de formação docente presente na oferta dos cursos analisados, sua inter-relação com o perfil dos egressos, estágios, atividades complementares, desenvolvimento e organização do curso, tratamento dos conteúdos curriculares, bem como a articulação dessas características com a qualidade do corpo docente e infraestrutura.

No que se referiu especificamente à qualidade do corpo docente do curso de pedagogia ofertado para alunos atendidos pelo Parfor, observou-se movimento desconexo entre os cursos. Nesse aspecto, foram valorizadas tanto a participação dos professores responsáveis pelas turmas do curso regular quanto a seleção e contratação de docentes fora dos quadros da universidade para suprir a demanda por oferta de vagas dentro do Parfor. No caso da contratação de professores, aspectos relativos à sua titulação e à avaliação posteriormente feita pelos alunos foram destacados como indicativos de qualidade. Já no caso de professores do quadro, a sua qualidade foi evidenciada por ter participado do processo de seleção da própria universidade, fazendo parte do seu corpo docente permanente. Em ambos os casos, não ficou muito clara a participação e envolvimento dos docentes em torno do projeto pedagógico do curso como indicativo de qualidade. Além disso, apesar de a contratação de professores fora dos quadros das IES para atender às turmas de alunos do Parfor ter sido mais comum entre aquelas instituições com maior número desses alunos, tal procedimento também foi observado nas IES com poucos alunos do programa, obedecendo aparentemente a uma necessidade interna de ajuste, do que se configurando, efetivamente, como uma decisão em prol da qualidade da formação dos alunos-professores.

Em relação aos aspectos relativos à infraestrutura como indicador de qualidade, apenas um dos coordenadores entrevistados teceu comentário. Nesse caso específico, a biblioteca e os equipamentos de auxílio didático foram citados como aspectos importantes para a formação do discente. Porém, para a maior parte 
dos coordenadores, a infraestrutura do curso não mereceu referências como indicador de qualidade.

Por fim, depreendeu-se que, apesar de operacionalmente ter sido possível caracterizar a oferta dos cursos presenciais de pedagogia no âmbito do Parfor por meio de indicadores não numéricos, a realidade concreta sinalizou para a inexistência de um padrão de qualidade organicamente compartilhado entre as licenciaturas analisadas. Com isso, as limitações do Sinaes no alcance regulatório desses cursos, aliadas à ausência de orientações do Parfor Presencial para subsidiar a atuação das instituições participantes, pareceram contribuir para imprecisões no significado de qualidade da oferta analisada.

\section{Referências}

AGUIAR, Márcia Ângela da Silva et al. Diretrizes curriculares do curso de pedagogia no Brasil: disputas de projetos no campo da formação do profissional da educação. Educação \& Sociedade, Campinas, v. 27, n. 96, p. 819-842, out. 2006.

AGUIAR, Márcia Ângela da Silva; MELO, Márcia Maria de Oliveira. Pedagogia e as diretrizes curriculares do curso de pedagogia: polêmicas e controvérsias. Revista Linhas Críticas, Brasília, v. 11, n. 20, p. 119-138, jan./jun. 2005.

ARAÚJO, Viviane Patricia Colloca. A multiculturalidade nas políticas educacionais e a formação de professores: Brasil e Portugal. 2009. 436 p. Tese (Doutorado em Educação) - Universidade Federal de São Carlos, São Carlos, 2009.

BERTOLIN, Julio César Godoy. Avaliação da qualidade do sistema de educação superior brasileiro em tempos de mercantilização: período 1994-2003. 2007. 282 f. Tese (Doutorado em Educação) - Universidade do Rio Grande do Sul, Porto Alegre, 2007.

BRASIL. Decreto-Lei n 1.190, de 4 de Abril de 1939. Dá organização à Faculdade Nacional de Filosofia. Diário Oficial da União, Rio de Janeiro, 06 abr. 1939. Seção 1, p. 7929. Disponível em: < http://www2.camara.leg.br/>. Acesso em: 16 nov. 2011.

BRASIL. Ministério da Educação. Conselho Nacional de Educação. Resolução CNE/CP n 1, de 15 de maio de 2006, que institui Diretrizes Curriculares Nacionais para o Curso de Graduação em pedagogia, licenciatura. Brasília, DF: MEC, 2006. Disponível em: <http:// meclegis.mec.gov.br >. Acesso em 8 out. 2011.

BRASIL. Decreto $n^{\circ}$ 6.755, de 29 de janeiro de 2009. Institui a Política Nacional de Formação de Profissionais do Magistério da Educação Básica, disciplina a atuação da Capes no fomento a programas de formação inicial e continuada e dá outras providências. Diário Oficial [da] República Federativa do Brasil, Brasília, DF, 30 jan. 2009. Disponível em: <http://www.planalto. gov.br >. Acesso em: 16 jun. 2012.

BURLAMAQUI, Marco Guilherme Bravo. Avaliação e qualidade na educação superior: tendências na literatura e algumas implicações para o sistema de avaliação brasileiro. Estudos em Avaliação Educacional, São Paulo, v. 19, n. 39, jan./abr. 2008.

CAPES (Fundação Coordenação de Aperfeiçoamento de Pessoal de Nível Superior). Plano Nacional de Formação dos Professores da Educação Básica - Parfor Presencial. Manual Operativo, Brasília, DF, 27 ago. 2014. Disponível em: <http://www.capes.gov.br/ images/ stories/ download/ legislacao/ 2782014-MANUAL-OPERATIVO-PARFOR.pdf>. Acesso em: 10 dez. 2014.

GATTI, Bernardete A. Documento contendo análises pedagógico-curriculares para os cursos de licenciatura vinculados às áreas de artes, biologia, história, língua portuguesa, matemática e pedagogia no âmbito da UAB e Parfor. Brasília, 2012. 54p. (Produto 2 apresentado à Unesco, referente ao Projeto 914BRZ1001.3 - Capes Fortalecimento da capacidade institucional com vistas ao incremento da educação básica, como resultado de Consultoria ao referido Projeto)

HARVEY, Lee; GREEN, Diana. Defining quality. Assessment \& Evaluation in Higher Education, London, v. 18, n. 1, p. 9-26, apr. 1993.

LIBÂNEO, José Carlos. Diretrizes curriculares da pedagogia: imprecisões teóricas e concepção estreita da formação profissional de educadores. Educação \& Sociedade, Campinas, v. 27, n. 96, Especial, p. 843-876, out. 2006. 
MINAYO, Maria Cecília de Souza. Construção de indicadores qualitativos para avaliação de mudanças. Revista Brasileira de Educação Médica, Rio de Janeiro, v. 33, n. 1, Suplemento 1, p. 83-91, 2009.

MINAYO, Maria Cecília de Souza. 0 desafio do conhecimento: pesquisa qualitativa em saúde. 13. ed. São Paulo: Hucitec, 2013. $407 \mathrm{p}$.

OCDE. Building a high-quality teaching profession: lessons from around the world. Paris: OECD, 2011. 65 p.

PIMENTA, Selma Garrido. 0 estágio na formação de professores: unidade entre a teoria e a prática. Cadernos de Pesquisa, São Paulo, n. 94, p. 58-73, ago. 1995.

PIMENTA, Selma Garrido; FRANCO, Maria Amélia Santoro; LIBÂNEO, José Carlos. Pedagogia, formação de professores - e agora? Problemas decorrentes das diretrizes curriculares nacionais para os cursos de pedagogia. In: DALBEN, Ângela Imaculada Loureiro de Freitas et al. (Org.). Convergências e tensões no campo da formação e do trabalho docente. Belo Horizonte: Autêntica, 2010. (Didática e prática de ensino). p. 831-852.

RIOS, Terezinha. Compreender e ensinar: por uma docência da melhor qualidade. 8. ed. São Paulo: Cortez, 2010. 158 p.

RODRIGUES, Marli de Fátima; KUENZER, Acácia Zeneida. As diretrizes curriculares para o curso de pedagogia: uma expressão da epistemologia da prática. Olhar de professor, Ponta Grossa, v. 10, n. 1, p. 35-62, 2007.

SCHÖN, Donald. Educando o profissional reflexivo: um novo design para o ensino e a aprendizagem. Porto Alegre: Artmed, 2000. 256p. (tradução: Roberto Cataldo Costa).

SOUSA, José Vieira de. Qualidade na educação superior: lugar e sentido na relação público-privado. Cadernos Cedes, Campinas, v. 29, n. 78, p. 242-256, maio/ago. 2009.

Recebido em: 03.06.2015

Aprovado em: 22.09.2015

Valdinei Costa Souza é doutora em educação e mestre em administração pela Universidade de Brasília. Realizou doutorado sanduíche na Fundação Carlos Chagas, sob orientação da Dra. Bernardete Gatti. É analista em ciência e tecnologia da Coordenação de Aperfeiçoamento de Pessoal de Nível Superior (Capes) onde atua na Diretoria de Relações Internacionais com 0 acompanhamento e monitoramento de resultados de políticas públicas. 